\title{
Continuing Weight-Loss Effect after Topiramate Discontinuation in Obese Persons with Schizophrenia: a Pilot Open-Label Study
}

Authors

Affiliations

\author{
C.-S. Liang ${ }^{1,2}$, F.-W. Yang ${ }^{2}$, S.-Y. Huang ${ }^{1,3}$, P.-S. Ho ${ }^{2}$
}

${ }^{1}$ Graduate Institute of Medical Sciences, National Defense Medical Center, Taipei, Taiwan, ROC

${ }^{2}$ Department of Psychiatry, Beitou Branch, Tri-Service General Hospital, National Defense Medical Center, Taipei, Taiwan, ROC ${ }^{3}$ Department of Psychiatry, Tri-Service General Hospital, National Defense Medical Center, Taipei, Taiwan, ROC

\section{Key words \\ - topiramate \\ - discontinuation \\ body weight \\ - leptin \\ - schizophrenia}

$\begin{array}{ll}\text { received } & 31.03 .2014 \\ \text { revised } & 27.04 .2014 \\ \text { accepted } & 13.05 .2014\end{array}$

Bibliography

DOI http://dx.doi.org/

10.1055/s-0034-1381984

Published online ahead of print:

17 June 2014

Pharmacopsychiatry 2014;

47: 162-168

(c) Georg Thieme Verlag KG

Stuttgart · New York

ISSN 0176-3679

\section{Correspondence}

Pei-Shen Ho, MD

Department of Psychiatry

Beitou Branch

Tri-Service General Hospital

National Defense Medical

Center

No. 60 Xinmin Road

Beitou District

Taipei City 112

Taiwan

ROC

Tel.: + 886/2/28959808

Fax: $+886 / 2 / 28957633$

chih1005@hotmail.com.tw

\section{Abstract \\ v}

Introduction: Few studies have investigated the likelihood of weight maintenance in obese persons with schizophrenia after their initial successful weight loss. This pilot open-label study examined the efficacy of topiramate in weight loss and the trajectory of weight changes after topiramate discontinuation.

Methods: This study enrolled 10 obese persons with schizophrenia. A 4-month treatment phase was started, followed by a 12-month discontinuation phase. Body weight was measured as the primary outcome every month. Secondary outcomes included leptin levels, fasting glucose, lipid profiles, and insulin resistance index.

\section{Introduction}

\section{$\nabla$}

Topiramate is an anticonvulsant approved for the treatment of epilepsy and migraine prophylaxis [1]. The proposed pharmacological mechanisms of topiramate include a decrement of neuronal excitation, an enhancement of $\gamma$-aminobutyric acid (GABA) activity at a non-benzodiazepine site on $G_{A B A}$ receptors, an increase in GABA-mediated chloride channels, a modulation of voltagedependent sodium and calcium channels, a blockade of kainate/AMPA glutamate receptor, and an increase in the potassium conductance [2]. The efficacy of topiramate has been reported in several psychiatric conditions, such as psychotic disorders [3,4], bipolar disorder [3], and substance-related disorders $[3,5]$. Appetite suppression and weight loss are common adverse effects in persons treated with topiramate [1-3]. In this sense, the pursuit of whether topiramate is a potential weight-loss drug for overweight persons has been the focus of many investigations.
Results: After the 4-month addition of topiramate, participants lost $1.79 \mathrm{~kg}$ of their body weight (95\% CI $=-3.03$ to $-0.56, p=0.005)$. The maximum weight reduction was $4.32 \mathrm{~kg}$, occurring when topiramate had been discontinued for 12 months $(95 \% \mathrm{CI}=-6.41$ to $-2.24, p<0.001)$.

Discussion: The continuing weight-loss effect after topiramate discontinuation might have resulted from topiramate's potential to improve leptin functioning. These findings demonstrate that topiramate's weight-loss effect could not only persist during its administration, but also continue to improve after its discontinuation.

The prevalence of metabolic syndrome in persons with schizophrenia is as much as 2-fold higher than that in the general population $[6,7]$. Obesity, among the components of metabolic syndrome, has been clearly demonstrated to be the major driving force leading not only to insulin resistance but also to cardiovascular disease risk [8]. Attention has been paid to the efficacy of topiramate in the management of overweight persons with schizophrenia, and the preliminary data are promising both in the prevention of weight gain $[9,10]$ and in weight reduction $[11,12]$.

Nevertheless, in addition to the extent of weight loss that the weight-loss agents could bring about, clinicians are interested to know whether the improved body weight could be sustained, and how long these agents need to be taken. Few studies so far have explored the likelihood of these weight-loss drugs in the maintenance of weight loss. Most of all, it is unknown whether weight regain would occur after discontinuing these drugs. A previous study found that in 
persons with schizophrenia receiving olanzapine therapy, the improved body weight could not be sustained after discontinuing sibutramine, an approved weight-loss drug [13]. Recently, another study addressing metformin discontinuation reported similar negative findings in non-diabetic patients with schizophrenia treated with clozapine [14]. Indubitably, the challenge to find an appropriate approach for maintenance of weight loss in schizophrenia remains.

So far there are no studies investigating whether and over how long a period weight loss could be sustained after topiramate discontinuation. Only one case report suggested weight rebound after topiramate cessation [15]. This pilot study aimed to evaluate the overall efficacy of topiramate for weight management in non-diabetic, overweight individuals with schizophrenia. The study investigating the effects of metformin discontinuation recorded body weight only 24 weeks after metformin discontinuation [14], rendering the trajectory of weight changes unclear. In our study the primary outcome was the monthly weight changes during topiramate addition and after topiramate discontinuation. The secondary outcome measures included fasting leptin, lipid profiles, insulin resistance index, and adverse effects. The null hypothesis of the study was that weight loss produced by topiramate could not be sustained after discontinuing topiramate intervention.

\section{Methods}

$\nabla$

\section{Participants}

From January 2011 to March 2012 a total of 10 individuals with schizophrenia were judged eligible. Participants were recruited from the long-stay ward of the Beitou Branch, Tri-Service General Hospital, National Defense Medical Center, a psychiatric teaching hospital in Taiwan. The Institutional Review Board for the Protection of Human Subjects at the Tri-Service General Hospital approved the protocol. All participants were informed about the aims and other details of the study, and gave written informed consent in accordance with the National Health and Medical Research Council guideline. They were free to withdraw their participation at any time.

All participants were older than 20 years of age with a body mass index (BMI) exceeding $27 \mathrm{~kg} / \mathrm{m}^{2}$, were diagnosed with schizophrenia according to DSM-IV criteria, had been stable on current psychotropics for at least 6 months, and were non-diabetic and normotensive. Additionally, all participants were fully capable of comprehending the study's purpose, procedure, treatment, risk and possible benefits, alternative treatment, and their right to refuse to participate in this study.

Individuals were excluded if they had a history of another significant medical disorder (e.g., epilepsy); if they met criteria for substance-related disorders; if they had a history of suicidality (attempt or current ideation); if they were involved in a special diet or special physical exercise program for weight reduction; and/or if they had a history of exposure to topiramate, or were currently taking topiramate or other weight-loss drugs. Importantly, individuals who lost more than $5 \%$ of body weight within 3 months were excluded because these persons might be suitable for non-pharmacological interventions for their weight management.

\section{Study design}

An open-label, fixed-dose design was used. This pilot study consisted of 2 stages. The first stage was a 4-month treatment phase $\left(\mathrm{M}_{0}, \mathrm{M}_{1}, \mathrm{M}_{2}, \mathrm{M}_{3}\right.$, and $\left.\mathrm{M}_{4}\right)$, and the second stage was a 12-month follow-up phase $\left(M_{5}, M_{6}, M_{7}\right.$ to $\left.M_{16}\right)$, during which topiramate was discontinued and body weight was investigated every month. To ensure tolerance to gastrointestinal adverse effects, such as nausea and vomiting, a 4-week titration schedule was used. An initial daily dose of $25 \mathrm{mg}$ of topiramate was increased weekly, and if well-tolerated, increased to reach the target dose of $50 \mathrm{mg}$ of topiramate twice a day. The participants were withdrawn if intolerable adverse effects occurred or if the dose of the psychotropic was changed. Tobacco use and alcohol consumption were not allowed.

The study was implemented in the chronic ward, and all participants stayed in the hospital for more than 6 months. The daily caloric intake was around 2000 calories, and the ward menus were predesigned by a nutritionist. In our chronic ward, there was a daily routine of $30 \mathrm{~min}$ of moderate intensity physical activity. It has been suggested that compared with non-hospitalized patients or patients in acute care settings, chronically hospitalized patients had more consistent activities of daily living, more reliable adherence to medications, more similar diet content, and more limited access to their favorite foods or foods external to the hospital - all of which could eliminate confounders [16].

\section{Assessment}

Outcome measures included body weight, glucose, leptin, insulin, lipid profiles, and insulin resistance. Insulin resistance was calculated using the homeostasis model assessment insulin resistance (HOMA-IR: fasting glucose $[\mathrm{mmol} / \mathrm{L}] \times$ fasting insulin [mU/L]/22.5) [17]. Serum leptin levels were determined with a sensitive radioimmunoassay and were set into relationship to the BMI-adjusted reference range ( $\log _{10}$-scaled) of healthy men and women [18]. Venous blood samples were collected after an overnight fast, between $07.30 \mathrm{~h}$ and $09.00 \mathrm{~h}$. Scales for safety included the Udvalg for Kliniske Undersogelser Side Effect Rating Scale [19] and the 17-item Hamilton Depression Rating Scale [20]. Laboratory measures and scales for safety were assessed at baseline, 4 months after topiramate administration $\left(\mathrm{M}_{4}\right)$, and 3 months after topiramate discontinuation $\left(\mathrm{M}_{7}\right)$. All participants underwent measurements of height and weight by a digital weighing scales with height rods. Height was measured to the nearest $0.1 \mathrm{~cm}$ (shoes and socks removed). Body weight was measured to the nearest $0.1 \mathrm{~kg}$ every month with the participant wearing only a standard T-shirt (double extra large). A trained nurse blinded to the study protocol completed these measurements.

\section{Statistical analyses}

All statistical analyses were conducted with the Statistical Package for the Social Science software for Windows (Chicago, IL). Paired sample $t$-tests were used to evaluate each continuous variable for pre- to post-treatment change. Given that body weight was measured repeatedly on the same individual across time, generalized estimating equations (GEE) were employed, and the first-order autoregressive working correlation structure was chosen. GEE could accommodate the correlation of repeated measurements, account for within-subject dependence effects, use all available data points, and be sensitive to patterns of change over time. In the GEE model body weight measured every 
Table 1 Demographic and clinical characteristics in nondiabetic, overweight persons with schizophrenia.

\begin{tabular}{|c|c|c|c|c|c|c|c|c|c|}
\hline Case & Age & Sex & Education $^{\mathrm{a}}$ & Duration $^{\mathrm{a}}$ & BW $^{\mathbf{a}}$ & $\mathrm{BMI}^{\mathrm{b}}$ & MSc $^{c}$ & Daily dose of medications & Dose $^{d}$ \\
\hline 1 & 63 & M & 12 & 47 & 77.0 & 29.7 & yes & $\begin{array}{l}\text { risperidone } 6 \mathrm{mg} \text {, clotiapine } \\
40 \mathrm{mg} \text {, benzhexol } 4 \mathrm{mg} \text {, } \\
\text { lorazepam } 1 \mathrm{mg}\end{array}$ & 840 \\
\hline 2 & 58 & M & 8 & 28 & 89.6 & 30.3 & yes & $\begin{array}{l}\text { flupentixol } 6 \mathrm{mg} \text {, benzhexol } 5 \mathrm{mg} \text {, } \\
\text { estazolam } 2 \mathrm{mg}\end{array}$ & 360 \\
\hline 3 & 37 & M & 12 & 22 & 88.3 & 29.2 & yes & $\begin{array}{l}\text { quetiapine } 800 \mathrm{mg} \text {, chlorpro- } \\
\text { mazine } 500 \mathrm{mg} \text {, lithium } 900 \mathrm{mg} \text {, } \\
\text { flurazepam } 60 \mathrm{mg}\end{array}$ & 1500 \\
\hline 4 & 44 & $\mathrm{~F}$ & 7 & 16 & 78.1 & 32.1 & yes & $\begin{array}{l}\text { clozapine } 400 \mathrm{mg} \text {, lithium } \\
1200 \mathrm{mg} \text {, benzhexol } 5 \mathrm{mg} \text {, } \\
\text { lorazepam } 2 \mathrm{mg}\end{array}$ & 600 \\
\hline 5 & 52 & $\mathrm{~F}$ & 12 & 26 & 66.6 & 27.5 & no & $\begin{array}{l}\text { zotepine } 150 \mathrm{mg} \text {, benzhexol } \\
10 \mathrm{mg}\end{array}$ & 300 \\
\hline 6 & 50 & $\mathrm{~F}$ & 6 & 10 & 83.2 & 33.3 & no & clozapine $400 \mathrm{mg}$ & 600 \\
\hline 7 & 46 & $\mathrm{~F}$ & 12 & 29 & 69.1 & 27.7 & yes & $\begin{array}{l}\text { risperidone } 6 \mathrm{mg} \text {, estazolam } 2 \mathrm{mg} \text {, } \\
\text { flurazepam } 60 \mathrm{mg}\end{array}$ & 600 \\
\hline 8 & 54 & $\mathrm{~F}$ & 9 & 34 & 92.7 & 39.1 & no & $\begin{array}{l}\text { chlorpromazine } 100 \mathrm{mg} \text {, clon- } \\
\text { azepam } 4 \mathrm{mg} \text {, flurazepam } 30 \mathrm{mg}\end{array}$ & 100 \\
\hline 9 & 36 & $\mathrm{~F}$ & 6 & 21 & 77.1 & 30.5 & yes & $\begin{array}{l}\text { quetiapine } 600 \mathrm{mg} \text {, haloperidol } \\
5 \mathrm{mg} \text {, benzhexol } 5 \mathrm{mg} \text {, flurazepam } \\
60 \mathrm{mg}\end{array}$ & 1050 \\
\hline 10 & 51 & $\mathrm{~F}$ & 9 & 34 & 92.7 & 36.7 & yes & $\begin{array}{l}\text { risperidone } 4 \mathrm{mg} \text {, benzhexol } 5 \mathrm{mg} \text {, } \\
\text { clonazepam } 4 \mathrm{mg}\end{array}$ & 400 \\
\hline Mean & $49.1(8.6)$ & na & $9.3(2.5)$ & $26.9(10.5)$ & $81.5(9.4)$ & $31.6(3.8)$ & na & na & 635 (407.6) \\
\hline
\end{tabular}

$\mathrm{BW}=$ body weight; $\mathrm{BMI}=$ body mass index; $\mathrm{MS}=$ metabolic syndrome

aEducation and duration of illness were recorded in years, and body weight was measured in kilograms

bBody mass index was calculated as body weight divided by the square of the height (kilograms per square meter)

'The diagnosis of metabolic syndrome was made according to International Diabetes Federation Task Force Criteria

dThe dose of each antipsychotic was converted to chlorpromazine equivalents

' $T$ The mean and the standard deviation of each variable were presented

month was the dependent variable. Independent variables that were entered in the final model included a time effect, the baseline body weight, and the dose of antipsychotic that were converted to chlorpromazine equivalents [21]. Other laboratory measures not identified as covariates were not included in the GEE model, such as age, sex, the dose of lithium and anticholinergic, and the diagnosis of metabolic syndrome according to International Diabetes Federation Task Force Criteria [22]. The time effect implied each month investigation, including 4-month treatment phase $\left(\mathrm{M}_{0}, \mathrm{M}_{1}, \mathrm{M}_{2}, \mathrm{M}_{3}\right.$, and $\left.\mathrm{M}_{4}\right)$ and 12-month followup phase $\left(\mathrm{M}_{5}, \mathrm{M}_{6}, \mathrm{M}_{7}\right.$ to $\left.\mathrm{M}_{16}\right)$.

In addition to the first GEE model examining changes in body weight, a second GEE model was conducted to explore the effect of leptin on topiramate-associated weight loss. In the second GEE model, the dependent variable was the body weight, and the independent variables included a time effect, leptin levels, baseline body weight, and an interaction effect ([time]×[leptin]). The working correlation was first-order autoregression. Body weight changes in the second GEE model included only $\mathrm{M}_{0}$, $\mathrm{M}_{1}, \mathrm{M}_{2}, \mathrm{M}_{3}, \mathrm{M}_{4}$, and $\mathrm{M}_{7}$, as leptin levels were obtained only in these months.

\section{Results}

$\nabla$

\section{Monthly body weight changes}

Overall, topiramate was well tolerated. There were no serious adverse events, and no one discontinued medication due to adverse effects. No subject developed suicidal ideation. Of the 10 persons recruited in this pilot study, one patient dropped out on
$\mathrm{M}_{3}$ because of changes in the psychotropics. All participants' demographic and clinical characteristics are shown in $\bullet$ Table 1. For controlling the dose of antipsychotic in the GEE model, the dose of each antipsychotic was converted to chlorpromazine equivalents [21]. Table 2 and $\bullet$ Fig. 1 display the monthly weight changes from baseline. Participants significantly reduced their body weight from the second month $(B=-1.04$, S.E. $=0.43$, $95 \% \mathrm{CI}=-1.89$ to $-0.19, p=0.016)$, and after the 4 -month addition of topiramate, the body weight differed significantly from baseline body weight $(B=-1.79$, S.E. $=0.63,95 \% \mathrm{CI}=-3.03$ to $-0.56, p=0.005$ ). Topiramate was discontinued at the end of $\mathrm{M}_{4}$, and importantly, participants sustained the reduced body weight throughout the 12-month follow-up period (from $\mathrm{M}_{5}$ to $\left.M_{16}\right)$, with the exception of $M_{10}(B=-1.17$, S.E. $=0.69,95 \%$ $\mathrm{CI}=-2.51$ to $-0.17, p=0.088)$ and $\mathrm{M}_{12}(\mathrm{~B}=-1.55$, S.E. $=0.87,95 \%$ $\mathrm{CI}=-3.25$ to $0.15, p=0.074)$. Notably, the maximum weight loss occurred on $\mathrm{M}_{16}(\mathrm{~B}=-4.32$, S.E. $=1.06,95 \% \mathrm{CI}=-6.41$ to -2.24 , $p<0.001)$.

\section{Secondary outcome measures}

- Fig. 2 illustrates the secondary outcome measures. As noted, high-density lipoprotein levels were significantly improved from $38.44 \pm 7.23 \mathrm{mg} / \mathrm{dL}$ to $43.44 \pm 7.18 \mathrm{mg} / \mathrm{dL}$ after 4 -month treatment with topiramate ( $95 \% \mathrm{CI}=1.762$ to $8.238, t=3.56, \mathrm{df}=8, p=0.007$ ). The improved high-density lipoprotein levels could be sustained after 3 months of topiramate discontinuation $(45.11 \pm 5.89 \mathrm{mg} / \mathrm{dL}$, $95 \% \mathrm{CI}=2.636$ to $10.698, t=3.814, \mathrm{df}=8, p=0.005)$. The other secondary measures on $\mathrm{M}_{4}$ and $\mathrm{M}_{7}$, including fasting glucose, lowdensity lipoprotein, cholesterol, triglyceride, and HOMA-IR, did not significantly differ from those on baseline. 
Table 2 Monthly weight changes in 10 persons with schizophrenia receiving 4-month adjunctive therapy of topiramate. ${ }^{\mathrm{a}}$

\begin{tabular}{|c|c|c|c|c|c|c|c|}
\hline \multicolumn{8}{|c|}{$95 \%$ Wald Cl } \\
\hline Parameter & B & SE & Lower & Upper & Wald $x^{2}$ & df & $\mathbf{p}$ \\
\hline (Intercept) & 13.63 & 2.12 & 9.47 & 17.79 & 41.17 & 1 & $<0.001$ \\
\hline Month $0^{\mathrm{b}}$ & 0 & & & & & & \\
\hline Month 1 & -0.89 & 0.52 & -1.92 & 0.14 & 2.89 & 1 & 0.089 \\
\hline Month 2 & -1.04 & 0.43 & -1.89 & -0.19 & 5.76 & 1 & 0.016 \\
\hline Month 3 & -1.75 & 0.46 & -2.65 & -0.85 & 14.4 & 1 & $<0.001$ \\
\hline Month 4 & -1.79 & 0.63 & -3.03 & -0.56 & 8.07 & 1 & 0.005 \\
\hline Month 5 & -1.74 & 0.51 & -2.73 & -0.74 & 11.67 & 1 & 0.001 \\
\hline Month 6 & -1.35 & 0.54 & -2.41 & -0.3 & 6.37 & 1 & 0.012 \\
\hline Month 7 & -1.38 & 0.7 & -2.75 & -0.01 & 3.89 & 1 & 0.049 \\
\hline Month 8 & -1.45 & 0.65 & -2.72 & -0.18 & 5 & 1 & 0.025 \\
\hline Month 9 & -1.74 & 0.76 & -3.23 & -0.26 & 5.27 & 1 & 0.022 \\
\hline Month 10 & -1.17 & 0.69 & -2.51 & 0.17 & 2.91 & 1 & 0.088 \\
\hline Month 11 & -1.83 & 0.68 & -3.16 & -0.5 & 7.25 & 1 & 0.007 \\
\hline Month 12 & -1.55 & 0.87 & -3.25 & 0.15 & 3.2 & 1 & 0.074 \\
\hline Month 13 & -1.96 & 1 & -3.93 & 0.004 & 3.83 & 1 & 0.05 \\
\hline Month 14 & -3.79 & 1.15 & -6.04 & -1.54 & 10.9 & 1 & 0.001 \\
\hline Month 15 & -4.13 & 1.03 & -6.12 & -2.11 & 16.03 & 1 & $<0.001$ \\
\hline Month 16 & -4.32 & 1.06 & -6.41 & -2.24 & 16.51 & 1 & $<0.001$ \\
\hline Baseline BW & 0.87 & 0.02 & 0.82 & 0.91 & 1722.38 & 1 & $<0.001$ \\
\hline Dose $^{c}$ & -0.001 & 0.0006 & -0.002 & $2.6 \times 10^{-5}$ & 4.34 & 1 & 0.055 \\
\hline Age & -0.04 & 0.02 & -0.08 & 0.003 & 3.3 & 1 & 0.069 \\
\hline
\end{tabular}

$\mathrm{Cl}=$ confidence interval; $\mathrm{SE}=$ standard error; $\mathrm{BW}=$ body weight

${ }^{a}$ General estimating equations, with controlling for baseline body weight, the dose of antipsychotic, and age, were conducted to evaluate monthly weight changes in ten participants with schizophrenia

${ }^{\mathrm{b}}$ Month 0 is the beginning of topiramate treatment, and Month 5 is the first month after topiramate discontinuation

' The dose of each antipsychotic was converted to chlorpromazine equivalents

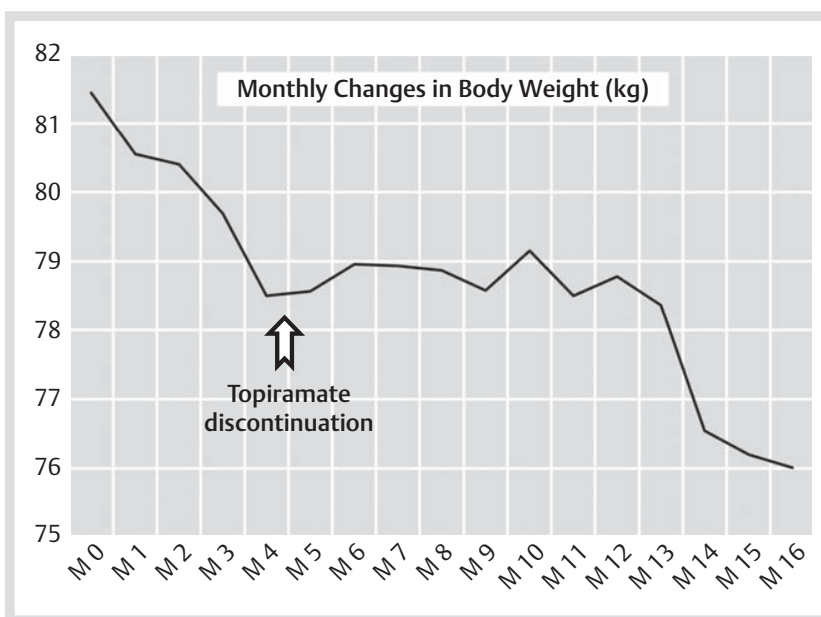

Fig. 1 Monthly changes in body weight in obese persons with schizophrenia treated with topiramate. M 0 is the baseline body weight, and M 5 is the first month after topiramate discontinuation. After the 4-month addition of topiramate, the participants significantly lost $1.79 \mathrm{~kg}$ of their body weight $(B=-1.79$, S.E. $=0.63,95 \% C l=-3.03$ to $-0.56, p=0.005)$. The reduced body weight was successfully sustained throughout the 12-month follow-up period, with the exception for $M 10(B=-1.17$, S.E. $=0.69,95 \% \mathrm{Cl}=-2.51$ to $-0.17, p=0.088)$ and $\mathrm{M} 12(\mathrm{~B}=-1.55$, S.E. $=0.87,95 \% \mathrm{Cl}=-3.25$ to $0.15, p=0.074)$. The maximum weight loss occurred on $M 16(B=-4.32$, S.E. $=1.06,95 \% C l=-6.41$ to -2.24 , $p<0.001)$.

\section{Interaction between topiramate discontinuation and leptin levels}

The second GEE model that evaluates the main effect of leptin on weight loss is shown in $\odot$ Table 3. If the interaction effect ([time]×[leptin]) was not included in the GEE model, leptin

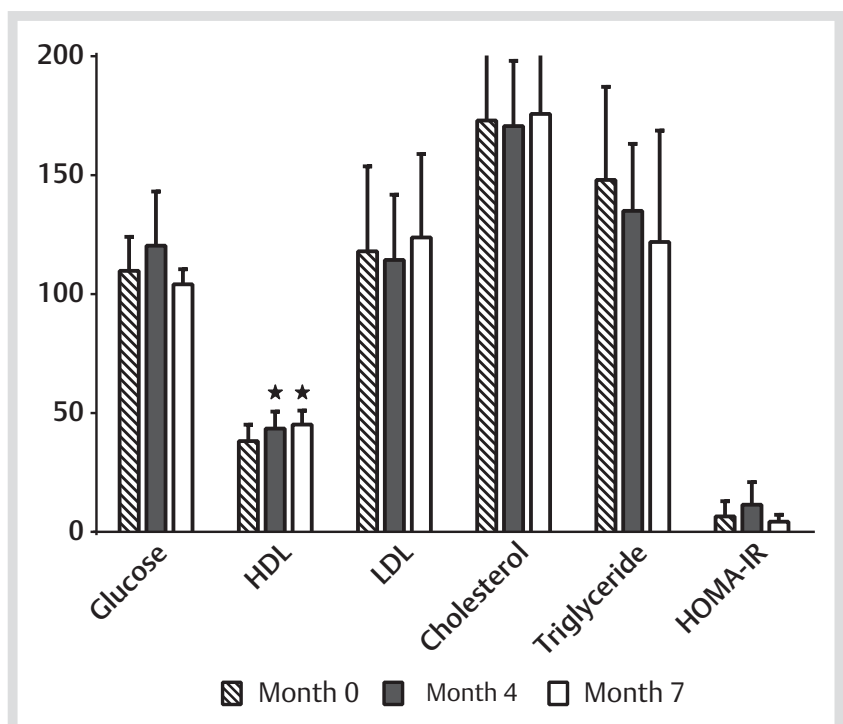

Fig. 2 Secondary outcomes were evaluated at baseline (Month 0 ), 4-month after topiramate administration (Month 4), and 3-month after topiramate discontinuation (Month 7). Compared with the baseline levels, only HDL levels at Month $4(t=3.56, \mathrm{df}=8, p=0.007)$ and Month 7 $(t=3.814, \mathrm{df}=8, p=0.005)$ reached statistical significance. Abbreviations: $\mathrm{HDL}=$ high-density lipoprotein; LDL = low-density lipoprotein; HOMA$\mathrm{IR}=$ homeostasis model assessment insulin resistance.

itself could exert the main effect $(B=0.032$, S.E. $=0.008,95 \%$ $\mathrm{CI}=0.016$ to 0.047 , Wald $\mathrm{X}^{2}=15.45, p<0.001$ ). Nevertheless, when the interaction effect was included, as noted in the - Table 3, the main effect of leptin did not reach statistical significance $(B=0.004$, S.E. $=0.01,95 \% \mathrm{CI}=-0.02$ to 0.003 , Wald $\left.\mathrm{X}^{2}=0.11, p<0.739\right)$. The interaction effect was statistically 
Table 3 General estimating equations assessing the effect of leptin on topiramate-associated weight loss in 10 persons with schizophrenia. ${ }^{\mathrm{a}}$

\begin{tabular}{|c|c|c|c|c|c|c|c|}
\hline \multirow[b]{2}{*}{ Parameter } & \multicolumn{6}{|c|}{ 95\% Wald Cl } & \multirow[b]{2}{*}{ p } \\
\hline & B & SE & Lower & Upper & Wald $x^{2}$ & df & \\
\hline (Intercept) & 6.06 & 1.5 & 3.11 & 9 & 16.23 & 1 & $<0.001$ \\
\hline Month $0^{b}$ & 0 & & & & & & \\
\hline Month 1 & -0.83 & 1.05 & -2.89 & 1.21 & 0.64 & 1 & 0.425 \\
\hline Month 2 & -1.91 & 0.63 & -3.16 & -0.67 & 9.12 & 1 & 0.003 \\
\hline Month 3 & -3.19 & 0.62 & -4.41 & -1.97 & 26.12 & 1 & $<0.001$ \\
\hline Month 4 & -3.89 & 0.84 & -5.55 & -2.24 & 21.28 & 1 & $<0.001$ \\
\hline Month 7 & -2.07 & 0.63 & -3.3 & -0.85 & 10.97 & 1 & 0.001 \\
\hline Baseline BW & 0.92 & 0.02 & 0.89 & 0.96 & 2840.02 & 1 & $<0.001$ \\
\hline Leptin & 0.004 & 0.01 & -0.02 & 0.03 & 0.11 & 1 & 0.739 \\
\hline Leptin * Month 0 & 0 & & & & & & \\
\hline Leptin * Month 1 & -0.002 & 0.02 & -0.05 & 0.04 & 0.01 & 1 & 0.916 \\
\hline Leptin * Month 2 & 0.02 & 0.02 & -0.02 & 0.05 & 1.03 & 1 & 0.31 \\
\hline Leptin * Month 3 & 0.04 & 0.01 & 0.01 & 0.07 & 8.43 & 1 & 0.004 \\
\hline Leptin * Month 4 & 0.06 & 0.02 & 0.02 & 0.09 & 9.08 & 1 & 0.003 \\
\hline Leptin * Month 7 & 0.18 & 0.03 & 0.13 & 0.24 & 45.37 & 1 & $<0.001$ \\
\hline
\end{tabular}

$\mathrm{Cl}=$ confidence interval; $\mathrm{SE}=$ standard error; $\mathrm{BW}=$ body weight

aThe general estimating equations included baseline body weight and leptin levels as covariates

${ }^{\mathrm{b}}$ Month 0 is the beginning of topiramate treatment, and Month 7 is the 3-month follow-up after topiramate discontinuation

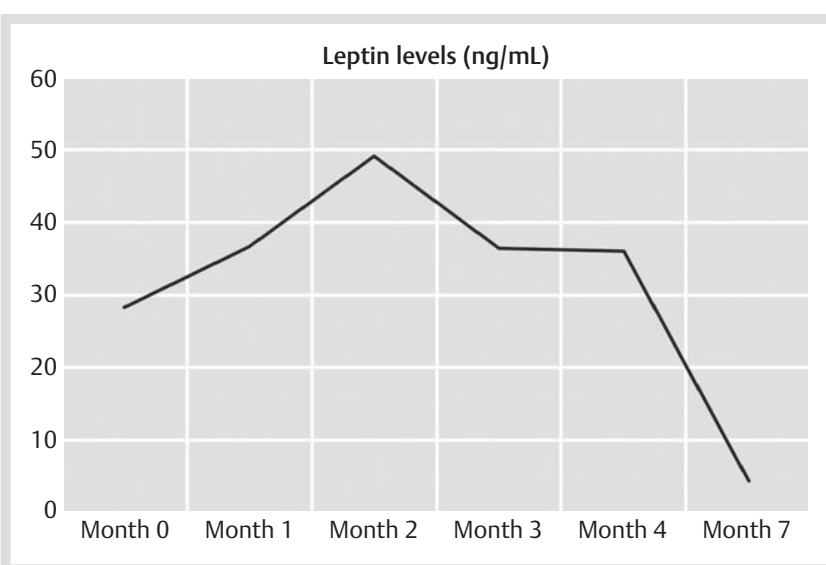

Fig. 3 Leptin levels were measured at baseline (Month 0), during the 4-month addition of topiramate (Month 1 to Month 4), and at 3-month follow-up after topiramate discontinuation (Month 7). Only at Month 2 $(t=-3.08, \mathrm{df}=9, p=0.013)$ and Month $7(t=3.727, \mathrm{df}=8, p=0.006) \mathrm{did}$ leptin levels significantly differ from those at baseline.

significant on $\mathrm{M}_{3}, \mathrm{M}_{4}$, and $\mathrm{M}_{7}$. $\odot$ Fig. 3 depicts the trends of leptin levels on $\mathrm{M}_{0}, \mathrm{M}_{1}, \mathrm{M}_{2}, \mathrm{M}_{3}, \mathrm{M}_{4}$, and $\mathrm{M}_{7}$. Leptin levels on $\mathrm{M}_{7}$ were significantly different from those on $\mathrm{M}_{4}(95 \% \mathrm{CI}=-53.467$ to $-9.889, t=-3.535, \mathrm{df}=8, p=0.01)$ and $\mathrm{M}_{0}(95 \% \mathrm{CI}=-36.08$ to $-8.5, t=-3.727, \mathrm{df}=8, p=0.006)$, but leptin levels on $\mathrm{M}_{4}$ did not differ significantly from those on $\mathrm{M}_{0}(95 \% \mathrm{CI}=-3.161$ to $21.94, t=1.725, \mathrm{df}=8, p=0.007)$. The Cohen's $d$ effect size of the change in leptin levels from $\mathrm{M}_{0}$ to $\mathrm{M}_{7}$ is 1.85 .

\section{Discussion}

$\nabla$

One of the major difficulties with treating obesity is that even after initial successful weight loss, most persons relapse into their previous unhealthy eating habits, thereby leading to weight regain. This study represents an attempt to explore, after the discontinuation of topiramate, how long the overweight persons with schizophrenia would maintain their body weight. After the 4-month addition of topiramate $100 \mathrm{mg} / \mathrm{d}$, the participants significantly lost $1.79 \mathrm{~kg}$ of their body weight $(95 \% \mathrm{CI}=-3.03$ to -0.56 ), and the weight-loss effect could be observed from the second month. This finding is somewhat similar to those derived from studies addressing the efficacy of topiramate in the management of overweight persons with schizophrenia [9-11]. However, an intriguing, and important, finding emerged - even though topiramate had been discontinued, the weight-loss effect persisted. The maximum weight reduction was $4.32 \mathrm{~kg}$, occurring when topiramate had been discontinued for 12 months. These findings clearly suggest that weight-loss effect could not only persist during topiramate administration but also continued to improve despite topiramate discontinuation. The mechanisms of topiramate-associated weight loss have been discussed in detail elsewhere $[2,11]$; in this paper, therefore, we emphasize the possible mechanisms contributing to continuing weight-loss effect after topiramate discontinuation.

The first mechanism might be attributed to the improvement in leptin resistance. Leptin is the primary adipose hormone that provides adiposity signal to brain, which could result in reducing food intake and increasing energy expenditure [23,24]. Nevertheless, obese persons generally have markedly elevated, rather than decreased, leptin levels. The coexistence of obesity and an unusually high circulating concentration of leptin has been linked to leptin resistance [23-25], a condition similar to insulin resistance. Leptin resistance is an important component in the development and maintenance of obesity [23-25]. Additionally, leptin resistance and obesity may aggravate each other, causing a vicious cycle to develop. In this scenario, restoration of leptin functioning might be a therapeutic target to successfully cut off this vicious cycle. An animal study published recently reported the efficacy of topiramate in improving leptin functioning [26]. The involved molecular mechanisms are to enhance leptin signaling to the brain and increase hypothalamic expression of anorexigenic neuropeptides. Given leptin resistance as a consequence of defects in leptin signaling and impairment in the hypothalamic neural circuitry $[23,25]$, topiramate theoretically improves leptin resistance, thereby leading to continued weight loss. 
The second mechanism of topiramate responsible for continuing weight-loss effect might be related to the modulation of corticomesolimbic dopamine function [27]. Like alcoholism in which decreased dopamine $D_{2}$ receptor availability correlates with cue reactivity and craving [28], obese individuals are found to have decreased striatal $D_{2}$ receptor availability $[29,30]$. The reduced basal activity of mesolimbic dopamine system might predispose them to attribute greater incentive salience to food cues, leaving them at more risk for compulsive eating. Several lines of evidence have supported the efficacy of topiramate in alcohol dependence $[31,32]$, and regulating cortico-mesolimbic dopamine function is one of the proposed mechanisms [27]. Therefore, after 4-month treatment with topiramate, the restored mesolimbic dopamine tone might theoretically abate the hyperreactivity of the mesolimbic system toward reward-predicting cues, thus adapting our patient's motivation to eat palatable food.

In our study, after 3 months of topiramate discontinuation, leptin levels were decreased by $84.5 \%(4.4 \pm 6.7 \mathrm{ng} / \mathrm{mL})$ from a baseline value of $43.3 \pm 17 \mathrm{ng} / \mathrm{mL}$. The second GEE model indicated that in addition to baseline body weight, the interaction effect of [Month 7] $\times$ [leptin] contributed to the main proportion of variance of weight changes. The significant interaction effect clear suggests that after topiramate was discontinued for 3 months, the remarked reduction in leptin levels significantly affects weight changes. A previous study has reported the association between leptin levels and the percentage of weight decrease in persons with epilepsy taking topiramate [2]. Namely, persons who reduced more body weight had a more significant reduction of leptin levels after topiramate administration. In this study, the effect size for change in leptin levels is large (1.85). Taking the above points together, continuing weight-loss effect after topiramate discontinuation may be associated with the improvement of leptin resistance, the restoration of mesolimbic dopamine function, and the remarked changes in leptin levels. Data from previous studies addressing weight changes after discontinuation of weight-loss agents appear to stand in contrast to our findings. Either sibutramine [13] or metformin [14] demonstrates weight regain in obese persons with schizophrenia after their discontinuation. In this study, we hypothesize that topiramate discontinuation-associated continuing weight-loss effect results from the potential of topiramate to improve leptin functioning, decrease leptin levels, and restore mesolimbic dopamine function. One may question why metformin or sibutramine could not have continuing weight-loss effects after their discontinuation if both drugs do affect leptin in a similar way. Evidence suggests that metformin could decrease serum leptin levels [33], restore leptin sensitivity [34], and increase hypothalamic leptin receptor expression [35]. In the case of sibutramine, post-treatment leptin levels were decreased in some studies $[36,37]$, but increased in the other one [38]. Until now, research has not explored how these 2 weight-loss agents influence mesolimbic dopamine system. Moreover, few head-to-head studies have compared the extent to which these 2 drugs affect leptin functioning and leptin levels, not to mention the other molecular mechanisms contributing to weight-controlling properties. It is clear that further studies designed in a head-to-head manner into the differences among weight-loss agents would be interesting and provide a hint to solve the puzzle.

We advise to exercise caution while interpreting the findings from this study. First, our sample size was small, which may have reduced the stability of estimates and led to wide confidence intervals. Based on an alpha of 0.05 , a power of 0.8 , an effect size of 0.665 for weight changes, and a 2-sided paired $t$-test, a sample size of 20 was determined. In the same manner with an effect size of 1.85 for leptin changes, a sample size of 5 was obtained. Evidently, further study using a sample size larger than 20 could confirm our findings.

Second, weight loss was observed from the second month; however, at that time leptin levels were still so high, and the interaction effect ([time] $\times$ [leptin]) reached significance from the third month. Thus, there may be other underinvestigated mechanisms in this study leading to topiramate's weight-loss effect. Indeed, diverse pharmacological mechanisms have been associated with topiramate-induced weight loss [2,11], such as its antagonistic effect on kainite/AMPA glutamate receptor.

The third limitation is the fact that although the dose of the antipsychotic had been controlled, the liability among antipsychotics to induced weight gain is distinctly different [39]. In other words, it remains to be established which kinds of antipsychotic-associated weight gain are most manageable by topiramate. This study included 2 patients treated with the high potential weight gain antipsychotic, clozapine. Fourth, although chronically hospitalized patients might have more consistent activities of daily living and more similar diet contents, this study could be improved if we used eating scale, such as the 3-Factor Eating Questionnaire-R18 [40]. Assessing the aspects of eating behavior, including cognitive restraint, uncontrolled eating, and emotional eating, provides another approach to disentangle the mechanisms underlying continuing weight loss after topiramate discontinuation.

Fifth, leptin levels were obtained until 3-month follow-up after topiramate discontinuation; hence, it is unknown, since that time point, whether the interaction effect between topiramate discontinuation and leptin levels could have an impact on weight changes. Finally, the subjects in this study were non-diabetic and normotensive, so the efficacy of topiramate on weight reduction should be generalized with caution to other populations, such as obese individuals with well-established diabetes. Maintaining the weight loss is difficult to achieve for most persons, and in this respect, it may be even more difficult to do for persons with schizophrenia, consisting of negative symptoms and cognitive deficits as intrinsic parts of illness. This study demonstrates a sustained benefit of topiramate to reduce body weight in obese persons with schizophrenia. Above all, subjects revealed continued reductions in body weight and leptin levels even after topiramate had been discontinued for 12 months. We suggest, based on previous evidence and our present findings, that continuing weight-loss effect after topiramate discontinuation might have resulted from topiramate's potential to improve leptin functioning, decrease leptin levels, and restore mesolimbic dopamine function.

We acknowledge that the small sample size and the lack of control group limit the generalizability of the findings. However, this study provides new evidence that in obese persons with schizophrenia, maintenance of weight loss after the discontinuation of weight-loss agents might be possible. To put this in perspective, a better understanding toward the overall mechanisms of topiramate and their interactions with leptin is thus of significant importance. We believe that this pilot study should be replicated because of the encouraging results. Further investigation is necessary to determine the efficacy of higher doses of topiramate in weight management and its impact on leptin functioning, and to evaluate the potential continuing weightloss effect in different populations. 


\section{Acknowledgements}

$\nabla$

This study was supported by grants from Civilian Administration Division of Beitou Branch, Tri-Service General Hospital, National Defense Medical Center. The Civilian Administration Division had no further role in study design; in the collection, analysis and interpretation of data; in the writing of the report; and in the decision to submit the paper for publication.

\section{Conflict of Interest}

$\nabla$

The authors declare no conflicts of interest.

\section{References}

1 Silberstein SD, Ben-Menachem E, Shank RP et al. Topiramate monotherapy in epilepsy and migraine prevention. Clin Ther 2005; 27: 154-165

2 Verrotti A, Scaparrotta A, Agostinelli S et al. Topiramate-induced weight loss: a review. Epilepsy Res 2011; 95: 189-199

3 Arnone D. Review of the use of Topiramate for treatment of psychiatric disorders. Ann Gen Psychiatry 2005; 4: 5

4 Hahn MK, Remington G, Bois D et al. Topiramate augmentation in clozapine-treated patients with schizophrenia: clinical and metabolic effects. J Clin Psychopharmacol 2010; 30: 706-710

5 Rubio G, Ponce G, Jimenez-Arriero MA et al. Effects of topiramate in the treatment of alcohol dependence. Pharmacopsychiatry 2004; 37 : 37-40

6 De Hert MA, van Winkel R, Van Eyck D et al. Prevalence of the metabolic syndrome in patients with schizophrenia treated with antipsychotic medication. Schizophr Res 2006; 83: 87-93

7 Sugawara N, Yasui-Furukori N, Sato Y et al. Prevalence of metabolic syndrome among patients with schizophrenia in Japan. Schizophr Res 2010; 123: 244-250

$8 \mathrm{Kahn} \mathrm{R,} \mathrm{Buse} \mathrm{J,} \mathrm{Ferrannini} \mathrm{E} \mathrm{et} \mathrm{al.} \mathrm{The} \mathrm{metabolic} \mathrm{syndrome:} \mathrm{time}$ for a critical appraisal: joint statement from the American Diabetes Association and the European Association for the Study of Diabetes. Diabetes Care 2005; 28: 2289-2304

$9 \mathrm{Kim} \mathrm{JH}, \mathrm{Yim}$ SJ, Nam JH. A 12-week, randomized, open-label, parallelgroup trial of topiramate in limiting weight gain during olanzapine treatment in patients with schizophrenia. Schizophr Res 2006; 82: $115-117$

10 Narula PK, Rehan HS, Unni KE et al. Topiramate for prevention of olanzapine associated weight gain and metabolic dysfunction in schizophrenia: a double-blind, placebo-controlled trial. Schizophr Res 2010; 118: 218-223

$11 \mathrm{Ko} Y H$, Joe SH, Jung IK et al. Topiramate as an adjuvant treatment with atypical antipsychotics in schizophrenic patients experiencing weight gain. Clin Neuropharmacol 2005; 28: 169-175

12 Jarskog LF, Hamer RM, Catellier DJ et al. Metformin for weight loss and metabolic control in overweight outpatients with schizophrenia and schizoaffective disorder. Am J Psychiatry 2013; 170: 1032-1040

13 Henderson DC, Copeland PM, Daley TB et al. A double-blind, placebocontrolled trial of sibutramine for olanzapine-associated weight gain. Am J Psychiatry 2005; 162: 954-962

14 Chen $\mathrm{CH}$, Huang MC, Kao CF et al. Effects of adjunctive metformin on metabolic traits in nondiabetic clozapine-treated patients with schizophrenia and the effect of metformin discontinuation on body weight: a 24-week, randomized, double-blind, placebo-controlled study. J Clin Psychiatry 2013; 74: e424-e430

15 Khazaal Y, Zullino DF. Rebound of weight gain following topiramate cessation. Pharmacopsychiatry 2007; 40: 85-86

16 Bai YM, Lin CC, Chen JY et al. Association of weight gain and metabolic syndrome in patients taking clozapine: an 8-year cohort study. J Clin Psychiatry 2011; 72: 751-756

17 Matthews DR, Hosker JP, Rudenski AS et al. Homeostasis model assessment: insulin resistance and beta-cell function from fasting plasma glucose and insulin concentrations in man. Diabetologia 1985; 28 : 412-419
18 Blum WF. Leptin: the voice of the adipose tissue. Horm Res Paediatr 1997; 48: 2-8

19 Lingjaerde O, Ahlfors UG, Bech P et al. The UKU side effect rating scale. A new comprehensive rating scale for psychotropic drugs and a crosssectional study of side effects in neuroleptic-treated patients. Acta Psychiatr Scand 1987; 334 (Suppl): 1-100

20 Hamilton $M$. A rating scale for depression. J Neurol Neurosurg Psychiatry 1960; 23: 56-62

21 Gardner DM, Murphy AL, O'Donnell $H$ et al. International consensus study of antipsychotic dosing. Am J Psychiatry 2010; 167: 686-693

22 Alberti KG, Eckel RH, Grundy SM et al. Harmonizing the metabolic syndrome: a joint interim statement of the International Diabetes Federation Task Force on Epidemiology and Prevention; National Heart, Lung, and Blood Institute; American Heart Association; World Heart Federation; International Atherosclerosis Society; and International Association for the Study of Obesity. Circulation 2009; 120: 1640-1645

23 Myers MG, Cowley MA, Munzberg H. Mechanisms of leptin action and leptin resistance. Annu Rev Physiol 2008; 70: 537-556

24 Munzberg H, Bjornholm M, Bates SH et al. Leptin receptor action and mechanisms of leptin resistance. Cell Mol Life Sci 2005; 62: 642-652

25 Morris DL, Rui L. Recent advances in understanding leptin signaling and leptin resistance. Am J Physiol Endocrinol Metab 2009; 297: E1247-E1259

26 Caricilli AM, Penteado E, de Abreu LL et al. Topiramate treatment improves hypothalamic insulin and leptin signaling and action and reduces obesity in mice. Endocrinology 2012; 153: 4401-4411

27 Johnson BA. Topiramate-induced neuromodulation of cortico-mesolimbic dopamine function: a new vista for the treatment of comorbid alcohol and nicotine dependence? Addict Behav 2004; 29: 1465-1479

28 Heinz A, Siessmeier T, Wrase J et al. Correlation between dopamine $\mathrm{D}(2)$ receptors in the ventral striatum and central processing of alcohol cues and craving. Am J Psychiatry 2004; 161: 1783-1789

29 Wang GJ, Volkow ND, Logan J et al. Brain dopamine and obesity. Lancet 2001; 357: 354-357

30 Wang GJ, Volkow ND, Thanos PK et al. Imaging of brain dopamine pathways: implications for understanding obesity. J Addict Med 2009; 3: $8-18$

31 Kenna GA, Lomastro TL, Schiesl A et al. Review of topiramate: an antiepileptic for the treatment of alcohol dependence. Curr Drug Abuse Rev 2009; 2: 135-142

32 Arbaizar B, Diersen-Sotos T, Gomez-Acebo I et al. Topiramate in the treatment of alcohol dependence: a meta-analysis. Actas Esp Psiquiatr 2010; 38: 8-12

33 Fruehwald-Schultes B, Oltmanns KM, Toschek B et al. Short-term treatment with metformin decreases serum leptin concentration without affecting body weight and body fat content in normal-weight healthy men. Metabolism 2002; 51: 531-536

34 Kim YW, Kim JY, Park YH et al. Metformin restores leptin sensitivity in high-fat-fed obese rats with leptin resistance. Diabetes 2006; 55: 716-724

35 Aubert G, Mansuy V, Voirol MJ et al. The anorexigenic effects of metformin involve increases in hypothalamic leptin receptor expression. Metabolism 2011; 60: 327-334

36 Karabacak IY, Karabacak O, Toruner FB et al. Treatment effect of sibutramine compared to fluoxetine on leptin levels in polycystic ovary disease. Gynecol Endocrinol 2004; 19: 196-201

37 Baranowska B, Wolinska-Witort E, Martynska L et al. Sibutramine therapy in obese women - effects on plasma neuropeptide Y (NPY), insulin, leptin and beta-endorphin concentrations. Neuro Endocrinol Lett 2005; 26: 675-679

38 Abo-Elmatty DM, Zaitone SA. Topiramate induces weight loss and improves insulin sensitivity in dietary obese rats: comparison to sibutramine. Eur Rev Med Pharmacol Sci 2011; 15: 1187-1195

39 Tschoner A, Engl J, Rettenbacher $M$ et al. Effects of six second generation antipsychotics on body weight and metabolism - risk assessment and results from a prospective study. Pharmacopsychiatry 2009; 42: 29-34

40 de Lauzon B, Romon $M$, Deschamps $V$ et al. The Three-Factor Eating Questionnaire-R18 is able to distinguish among different eating patterns in a general population. J Nutr 2004; 134: 2372-2380 